\title{
Análise da relação entre valor de mercado e divulgação do relatório de sustentabilidade: um estudo nas empresas de alto potencial poluidor
} listadas na B3

\section{Analysis of the relationship between market value and disclosure of the} sustainability report: a study of high-potential pollution companies listed on the B3

Marina Alves Rodrigues da Silveira Alves ${ }^{1}$

Risolene Alves de Macena Araújo ${ }^{2}$

Lívia Maria da Silva Santo 3

\section{Resumo}

Esta pesquisa teve como objetivo analisar a relação entre valor de mercado das empresas de alto potencial poluidor listadas na $\mathrm{B} 3$ e a divulgação voluntária do relatório de sustentabilidade. A amostra da pesquisa é formada por 37 companhias de capital aberto com ações negociadas na B3, e pertencentes aos setores de alto potencial poluidor, segundo a Lei $\mathrm{n}^{\circ} 10.165 / 2000$. Para alcançar o objetivo desta pesquisa, utilizou-se a análise de conteúdo para examinar a divulgação voluntária do relatório de sustentabilidade (DIVRS), no período de 2012 a 2016, bem como a aplicação de regressão múltipla. O resultado não apresentou significância estatística entre a variável independente (DIVRS) e o valor de mercado das empresas, bem como um sinal negativo do coeficiente, ou seja, apresentou relação indireta entre essas variáveis. Sendo assim, houve a rejeição da hipótese de pesquisa (H1: O valor de mercado das empresas de alto potencial poluidor listadas na B3 esta positivamente relacionada com a divulgação voluntária do relatório de sustentabilidade.). Tal resultado contraria a premissa que o fato da empresa divulgar o relatório de sustentabilidade exerceria influência positiva no valor de mercado das empresas. No tocante às demais variáveis (ENDIV, RENT, CRES), elas foram significantes, sendo o endividamento (ENDIV) refletido de forma positiva, enquanto que a rentabilidade (RENT) e crescimento da empresa (CRES), refletidas de forma negativa sobre o valor de mercado; a variável tamanho (TAM) não apresentou significância estatística; e a variável ISE foram omitidas do modelo econométrico por se tratarem de dummies fixas ao longo do painel.

Palavras-chaves: Divulgação Voluntária. Valor de Mercado. Sustentabilidade.

\footnotetext{
${ }^{1}$ Bacharel em Ciências Contábeis.

${ }^{2}$ Mestre em Ciências Contábeis, Professora da Faculdade Unifuturo.

${ }^{3}$ Mestre em Ciências Contábeis, Membro do Grupo de Pesquisa em Contabilidade e Educação Financeira (GCFIN/UFPB).
} 


\begin{abstract}
This research had as objectiveanalyzing the relation between market value of the high polluting potential companies listed onB3 and the voluntary disclosure of the sustainability report. The research sample consists of 37 publicly traded companies with shares traded on the B3 and belonging to sectors with high potential for pollution, according to law $\mathrm{n}^{\circ}$. $10.165 / 2000$. In order to achieve the objective of this research, the content analysis was used to examine the voluntary disclosure of the sustainability report (DIVRS), between 2012 and 2016, as well as the application of multiple regression. The result did not present statistical significance between the independent variable (DIVRS) and the market value of the companies, as well as a negative sign of the coefficient, that is, presented an indirect relation between these variables. Thus, there was a rejection of the research hypothesis (H1: The market value of the high potential polluter companies listed in B3 is positively related to the voluntary disclosure of the sustainability report.). Such a result runs counter to the premise that the company's disclosure of the sustainability report would have a positive influence on the market value of the companies. Regarding the other variables (ENDIV, RENT, CRES), they were significant, with Indebtedness (ENDIV) being positively reflected, while Profitability and Company Growth (CRES), reflected negatively on the value of the market; the variable size (TAM) did not present statistical significance; and the ISE variable were omitted from the econometric model because they were fixed dummies along the panel.
\end{abstract}

Keywords: Disclosure.Sustainability Market Value.Voluntary.

\title{
Introdução
}

Em virtude das mudanças econômicas e tecnológicas, do descompasso quanto ao uso racional dos recursos naturais e do meio ambiente, as organizações passaram a desenvolver estratégias organizacionais que abarcassem as ações de responsabilidade social, desenvolvimento sustentável, consumo consciente e alcance das metas de resultado da empresa. Segundo Zaro, Pastre e Alberton (2015), isso ocorre devido à conscientização gerada na sociedade quanto aos impactos causados pelos processos produtivos empresariais ao meio ambiente.

Em meio a esse cenário, Monteiro e Ferreira (2007) destacam que o papel da contabilidade é evidenciar informações sobre fatos e eventos internos e externos à empresa, que podem afetar o meio ambiente e o patrimônio das organizações. Ou seja, a evidenciação dessas informações incorpora os princípios de responsabilidade social corporativa, que pregam a ética na condução dos negócios, a transparência no relacionamento com os stakeholders e o compromisso da empresa com o desenvolvimento sustentável (Souza, Rásia \& Jacques, 2010). 
As empresas utilizam-se, além da divulgação de demonstrativos de caráter compulsório, da divulgação de informações voluntárias para mitigar lacunas na informação quanto à evolução de suas políticas econômicas, financeiras e sociais (Slewinski, Gonçalves\& Sanches, 2015). Dentre as formas de evidenciação voluntária, no Brasil, destaca-se o Relatório de Sustentabilidade.

A elaboração e divulgação do relatório de sustentabilidade são voluntárias, inclusive às companhias que sofrem influências regulatórias; entretanto, estas são incentivadas a comunicar práticas socioambientais, cabendo aos gestores decidir por elaborar ou não o relatório de sustentabilidade(Lucena\& Pereira, 2016).A esse respeito, Sousa, Silva, Ribeiro \& Weffort (2014)mencionam que a evidenciação voluntária de investimentos ambientais tornouse rotina em muitas organizações, não só para cumprir regulamentações, mas, sobretudo, para demonstrar a preocupação ambiental e a responsabilidade social da empresa.

Assim, a fim de incentivar boas práticas de gestão e transparência no mercado de capitais, a Brasil, Bolsa, Balcão (B3 S.A.), por meio do Comunicado Externo 017/2011-DP, passou a recomendar que as empresas listadas indiquem, em seu Formulário de Referência, a partir de 2012,se publicam Relatório de Sustentabilidade, e em que site está disponível. Em caso negativo, devem explicar por que não o fazem (B3, 2017).

Todavia, Nagano, Kassai, Kussaba e Carvalho (2013) argumentam que a pressão externa pela divulgação das informações não financeiras não aconteceu somente pela preocupação da sociedade em relação ao desenvolvimento sustentável. Acontece que as informações financeiras, tradicionalmente divulgadas pelas organizações, passaram a não ser suficientes para a avaliação e a análise precisas do desempenho corporativo, tendo em vista que o valor da empresa está cada vez menos determinado por seus ativos financeiros, ou fixos, e cada vez mais por ativos intangíveis e outros (Nagano et al., 2013).

Em função do objetivo de ampliar o valor da empresa, as companhias tendem a divulgar "apenas" as notícias favoráveis, enquanto tardam as más, salvo, quando acreditarem que poderão sofrer alguma consequência danosa por parte de seus usuários, caso não as divulguem, uma vez que o investidor racional interpreta a não divulgação de uma informação como desfavorável, a respeito da empresa (Verrecchia, 2001).Assim, as práticas de 
divulgação normalmente são influenciadas pelo significado que assumem em determinado contexto social (Dias Filho, 2007).

Corroborando o exposto, Cintra (2011) menciona que a divulgação de informações ambientais é motivada pela busca por legitimidade organizacional, construção de imagem positiva da organização, para vender mais ou praticar preços mais altos no mercado interno e obter benefícios econômicos. Nesse sentido, Botelho (2006) também averiguou que existe relação entre o valor de mercado das empresas brasileiras e as notícias e informações que revelam responsabilidade social e ambiental.

Considerando as exigências dos stakeholders por informações socioambientais e sabendo-se que tais informações podem se constituir num diferencial para as organizações, inclusive no seu valor de mercado, emerge o problema de pesquisa: Qual é a relação entre o valor de mercado das empresas de alto potencial poluidor, listadas na B3, e a divulgação voluntária do Relatório de Sustentabilidade?

O objetivo do estudo é analisar a relação do valor de mercado das empresas de alto potencial poluidor, listadas na B3, e a divulgação voluntária do Relatório de Sustentabilidade.

Sob essa perspectiva, a presente pesquisa justifica-se, primeiramente, pelo tema estar diretamente ligado à postura das organizações frente ao gerenciamento dos riscos eminentes das atividades de alto potencial poluidor, regulamentado pela Lei 10.165/2000, que trata da Política Nacional do Meio Ambiente. Em segundo lugar, justifica-se pela importância da evidenciação de informações ambientais, como forma de prestação de contas aos stakeholders, representando, consequentemente, um diferencial competitivo no mercado (Souza,Rásia\& Jacques, 2010, Moreira, Gomes, Dias Filho \& Conceição,2014).

\section{Referencial Teórico}

\subsection{Teoria da Divulgação Voluntária}

O objetivo da contabilidade é prover informação útil para a tomada de decisão, independentemente se a divulgação tem previsão normativa (obrigatória)ou seé informação 
adicional(voluntária). Todavia, para que se consiga uma divulgação apropriada, é preciso responder três perguntas fundamentais: (i) a quem deve ser divulgada a informação?; (ii) qual é a finalidade da informação?;e (iii) quanta informação deve ser divulgada? (Hendriksen\&Breda, 1999).

A divulgação obrigatória é proveniente de alguma regulamentação que especifica os requisitos mínimos considerados aceitáveis de evidenciação (Dahlsrud, 2008), enquanto a informação voluntária pode ser entendida como sendo toda e qualquer informação econômica, financeira ou operacional, que não é, explicitamente, requerida pelas normas que regulam a elaboração dos relatórios financeiros, não tendo caráter obrigatório, que vem acrescentar valor à referida informação obrigatória aos investidores (Oliveira, Lopes \& Cunha, 2008, Rufino \& Monte, 2014).

De acordo com Verrecchia (2001),a divulgação voluntária de informações pode ser baseada em três categorias de pesquisa: i) Baseada em Associação: estuda a relação entre a divulgação voluntária e as alterações na conduta do investidor; ii)Baseada em Julgamento: investiga o motivo da divulgação, ou não, das informações voluntarias; e iii) Baseada em Eficiência: analisa as pesquisas nas quais as divulgações voluntarias são preferidas ou eficientes.

Salottie Yamamoto (2008) apontam que a divulgação, se obrigatória ou voluntária, gera discussões entre os pesquisadores: enquanto os favoráveis à obrigatoriedade afirmam que as empresas não fornecem informações suficientes aos investidores, os que defendem a divulgação voluntária acreditam haver nas empresas estímulos necessários para fornecer informações capazes de satisfazer os investidores. Nesse sentido, a divulgação voluntária desempenha um papel fundamental na administração do conflito de interesses e na redução da assimetria informacional existente entre gestores e investidores (Cunha \&Ribeiro, 2008).

No tocante às informações econômicas e socioambientais divulgadas pelas companhias, Ho (2005) menciona que existe certa pressão dos acionistas e da sociedade, visto que demandam das organizações mais accountabilitye transparência na divulgação de informações. Ademais, Nossa (2002) sugere que o setor em que a empresa atua também é um 
fator relevante para explicar o nível de divulgação de informações ambientais, uma vez que setores econômicos com potencial poluidor elevado sofrem maior pressão social.

Deegan (2002) apresenta algumas razões que podem estimular as organizações a divulgarem informações sociais e ambientais voluntariamente: (i) desejo de cumprir requisitos legais; (ii) a racionalidade econômica; (iii) a crença na responsabilidade de declarar informações ou prestar contas; (iv) exigências de empresas de financiamento; (v) atendimento às expectativas da sociedade; (vi) ameaças à legitimidade da entidade; (vii) gerenciamento de alguns grupos de stakeholders; (viii) atrair fundos de investimentos; (ix) evitar os esforços de inserção de regulamentações de divulgação mais onerosas; dentre outras.

Em suma, Deegan (2002) afirma que as corporações tendem a ampliar suas evidenciações voluntárias de informações ambientais e sociais, como forma estratégica de contribuir para fortalecer sua imagem de entidade comprometida com o bem-estar social e com a preservação das condições de sobrevivência no planeta, bem como recuperar sua legitimidade, principalmente quando abalada por eventos que possam ter prejudicado a sua imagem perante os stakeholders. Gordon,Loeb e Sohail (2010) complementam o exposto, ao alegarem que as divulgações de informações, em relatórios anuais, permitem que uma empresa forneça sinais ao mercado de que ela está ativamente envolvida na prevenção, detecção e correção de possíveis violações de segurança.

\subsection{Relatório de Sustentabilidade}

Relatório de sustentabilidade é um termo geral utilizado para descrever os instrumentos, ou relatórios, utilizados por organizações para a divulgação de informações referentes ao desempenho da organização de natureza sustentável, ou seja, as informações relacionadas aos temas ambiental, social e econômica. (Nagano et al., 2014).

Nagano et al. (2014) enfatizam, ainda, que o relatório de sustentabilidade deve apresentar, de maneira equilibrada e razoável, o desempenho sustentável da entidade; adicionalmente, um relatório de qualidade deve deixar claro o comprometimento da entidade quanto aos assuntos de natureza sustentável, bem como as estratégias adotadas para atingir seus objetivos em relação a estas questões. Sobre isso, Cruz (2005) enfatiza que as empresas 
buscam minimizar os impactos ambientais causados por suas atividades operacionais e dirigir ações que vão além da compensação dos impactos causados, de maneira a agregar valor, tornando-as mais conhecidas no mercado e satisfazendo os desejos empresariais e de consumo de seus stakeholders.

De acordo com Cunha e Ribeiro (2008), no ano de 1993, empresas de diversos setores passaram a divulgar, de forma mais recorrente, relatórios com um perfil mais social e humano, tornando os balanços sociais uma realidade para um número cada vez maior de empresas. Diversas organizações começaram a trabalhar, ostensivamente, com o tema, realizando seminários, palestras e cursos sobre ética, responsabilidade social e ambiental.

Conforme Bertoncello e Chang Junior (2007), isso ocorre por alguns motivos, tais como: (i) os clientes tornam-se mais orgulhosos de comprar produtos de uma empresa com elevada responsabilidade social; (ii) fornecedores sentem-se motivados em trabalhar como parceiros de uma empresa desta natureza; e (iii) o governo e a sociedade civil tornam-se parceiros desta empresa, sem seus empreendimentos sociais.

Alongo prazo, para a empresa possuir continuidade, ela deve atender às necessidades de todos os agentes envolvidos: clientes, fornecedores, financiadores, governos, comunidade, funcionários e acionistas. Dentre as necessidades, destaca-se o bem-estar dos próprios funcionários e da sociedade, com ênfase no aspecto ambiental (Tinoco, 2010).

Ao desenvolver ações de cunho social ou ambiental, as empresas buscam relacioná-las com suas atividades, e, para isso, utilizam ferramentas de marketing. Tais ações não são apenas divulgadas em mídias, mas, também, por meio de informações anuais em seus relatórios de sustentabilidade, que podem ser denominados de Balanço Social ou Relatório de Sustentabilidade.

Segundo o Global Reporting Initiative (GRI), os benefícios externos do relatório de sustentabilidade podem atenuar ou reverter os impactos negativos ambientais, sociais e de governança; melhorar a reputação e lealdade à marca; permitir que as partes externas interessadas entendam o verdadeiro valor da organização e dos ativos tangíveis e intangíveis; 
e demonstrar como as organizações influenciam e são influenciadas por expectativas de desenvolvimento sustentável.

O GRI lançou, em 2006, as Diretrizes G3, que apresentam Diretrizes para Relatório de Sustentabilidade, auxiliando a elaboração das demonstrações sustentáveis das empresas. Nelas contêm princípios e orientações para elaboração do relatório, e, também, para garantir um equilíbrio e qualidade do desempenho da organização, auxiliando e apontando quais informações devem conter nesses relatórios. Além disso, foram criados os "Principio de Conteúdo do Relatório" e os "Princípios para Assegurar a Qualidade do Relatório", cujos conteúdos estão contidos no G3.

Os princípios para definição de conteúdo do relatório são: i) Materialidade: define tópicos que reflitam os impactos econômicos, ambientais e sociais significativos da organização; ii) Inclusão dos Stakeholders: identificação dos stakeholders; iii) Contexto de Sustentabilidade: apresentação do desempenho da organização em um contexto mais amplo de sustentabilidade.

Para assegurar a qualidade dos relatórios, as informações contidas no mesmo deverão ser coerentes com os princípios, pois todos eles são fundamentais para uma transparência efetiva. A qualidade das informações possibilita que os stakeholders realizem avaliações de desempenho consistentes e justas e tomem as medidas adequadas (GRI, 2006).

Os princípios para assegurar a qualidade do relatório são: i) Equilíbrio: o relatório deve refletir aspectos positivos e negativos do desempenho da organização; ii) Comparabilidade: as questões e informações devem ser relatadas de forma consistente, a fim de serem analisadas as mudanças ao longo do tempo; iii) Exatidão: as informações devem ser precisas e detalhadas; iv) Periodicidade: a divulgação do relatório deve ser regularmente e disponibilizadas a tempo para auxiliar na tomada de decisões dos stakeholders; v)Clareza: as informações devem ser apresentadas de maneira clara e concisa; vi) Confiabilidade: as informações e a maneira como elas foram coletadas, registradas, analisadas e divulgadas de maneira que permita análise de terceiros. 
Vale ressaltar, que, no Brasil, não existe uma lei que obrigue as empresas a elaborar e divulgar os Relatórios de Sustentabilidade; entretanto, há o Projeto de Lei do Senado (PLS) 289/2012, que visa à obrigatoriedade para as empresas de capital aberto. Enquanto a PLS mencionada não entra em vigor, segue a teoria da voluntariedade na elaboração e divulgação de relatório de sustentabilidade às empresas brasileiras.

\subsection{Estudos anteriores}

Ao longo dos anos, diversas pesquisas abordaram a temática da evidenciação ambiental e desempenho das empresas, em especial, no contexto das empresas potencialmente poluidoras (Verrecchia, 2001, Salotti\& Yamamoto, 2008, Clarkson et al., 2008, Rover et al., 2009, Sousa et al., 2014, Nagaro et al., 2013,Andrade, Bressan, Iquiapaza\& Moreira, 2013, 2013; Rufino \& Monte, 2014, Lucena \& Pereira, 2016, Santos, Araújo \& Leite Filho, 2016).

Em sua pesquisa, Rover et al., (2009), ao estudarem as empresas listadas na BM\&FBovespa, pertencentes a setores de alto impacto, segundo a Lei $n^{\circ}$. 10.165/2000, buscaram analisar as demonstrações financeiras e os relatórios de sustentabilidade do período de 2005 a 2007.Os autores verificaram que,dentre as categorias ambientais evidenciadas no estudo, as "Políticas Ambientais" e as "Informações Financeiras Ambientais" foram as que mais tiveram ênfase. Além disso, notou-se que, de todas as categorias, com exceção das “'Informações Financeiras Ambientais”, as empresas de papel e celulose divulgaram mais informações ambientais do que as dos outros setores.

Ao analisar os fatores determinantes do nível de divulgação de informação voluntária das empresas, Rufino e Monte (2014) apontam, como resultado, a rentabilidade, o tamanho das empresas, a sustentabilidade, o endividamento, a liquidez das ações e a internacionalização. Em consonância, Clarksonet al. (2008) observaram, ao verificar a relação do disclosure ambiental e desempenho da empresa, que o melhor desempenho ambiental está associado com maior disclosure ambiental, o que implica dizer que, quanto mais informações boas sobre sua performance ambiental uma empresa tem, mais interesse ela possui em evidenciar isso. 
O estudo de Sousa et al., (2014) realizou uma análise entre o valor de mercado e o disclosure voluntário das companhias listadas na BM\&FBovespa, no período de 2007 a 2011. O estudo fez uma comparação entre a divulgação voluntária de informações econômicas, ambientais e sociais. Os resultados da pesquisa apontaram que há existência de relação significante e positiva entre a divulgação voluntaria de informações econômicas e valor de mercado das empresas; já em relação à divulgação voluntária ambiental, notou-se uma relação significante, porém negativa, e que não há evidências de relação significante sobre a divulgação voluntária de informações sociais, em relação ao valor de mercado.

Estudo semelhante ao de Sousa et al., 2014, foi desenvolvido por Santos et al. (2016), cujo objetivo foi investigar a influência da divulgação voluntária de informações econômicas, ambientais e sociais no valor de mercado das empresas da construção civil, listadas na BM\&FBOVESPA. Os resultados apontaram uma relação positiva significante entre o valor de mercado (VM) das empresas com a divulgação voluntária de informações econômicas (DIVE) e ambientais (DIVA); e uma relação negativa e significante entre o valor de mercado (VM) e a divulgação voluntária de informações sociais (DIVS). Observou-se, ainda, que o endividamento (END) e a rentabilidade (RENT) foram refletidos de forma positiva sobre o valor de mercado, enquanto que o crescimento da empresa (CRESC), auditagem por Big Four (AUD) e tamanho da empresa (TAM), refletidas de forma negativa sobre o valor de mercado.

O resultado da pesquisa de Santos et al. (2016) é consistente com outros estudos, como os de Verrecchia (2001) e Salotti e Yamamoto (2008), os quais afirmam existir uma relação positiva significativa entre a divulgação voluntária e o valor de mercado das empresas.

Acerca da temática explorada no presente trabalho, Nagaroet al. (2013) analisaram a evolução dos relatórios de sustentabilidade e a necessidade da obrigatoriedade de sua asseguração por terceiros. Verificou-se, como principal dificuldade de elaboração e verificação, a natureza das informações do relatório de sustentabilidade, pois, embora o GRI demonstre algumas informações através de indicadores de desempenho, o que permite a comparabilidade destas informações, a maior parte das informações de natureza sustentável ainda é qualitativa e de difícil mensuração. 
Por sua vez, Andrade et al. (2013) apresenta um estudo baseado nos determinantes de adesão ao ISE e sua relação com o valor da empresa. A pesquisa se baseou em possíveis variáveis de adesão ao ISE, como tamanho da empresa, endividamento, rentabilidade e valor de mercado. Os resultados obtidos demonstram que as empresas que têm maior tamanho, maior rentabilidade e são de setores considerados de alto impacto possuem maior probabilidade de aderirem à carteira ISE.

A pesquisa de Lucena e Pereira (2016) avaliaram os determinantes da divulgação voluntária das empresas de energia elétrica e telecomunicações listadas na BM\&FBovespa. Os autores identificaram que o número de empresas do setor de energia elétrica, que divulga o relatório de sustentabilidade, é maior do que aquelas que não o divulgam, sendo verificado o contrário no setor de telecomunicações. Outro ponto observado foi a influência da variável tamanho (TAM), que apresentou-se maior para as empresas que são divulgadoras do relatório de sustentabilidade,e o fato das médias das variáveis desempenho (DESEMP) e endividamento (END) serem maiores nas empresas que não divulgaram o relatório.

\subsection{Fundamentação da Hipótese}

A adaptação das empresas, em relação às práticas ambientais exigidas pelos diferentes stakeholders ,promove reflexos na gestão e na forma como elas informam suas interações com o meio ambiente (Rover, Borba\&Murcia, 2009). Nesse sentido, o estudo da evidenciação ambiental se faz necessário, uma vez que as organizações se utilizam dessa forma de comunicação, para ajudar os seus diversos usuários nas suas tomadas de decisões, além de ser um diferencial competitivo no setor em que atuam (Huang \& Kung, 2010, Lima, Cunha, Moreira \& Porte, 2012).

Sobre isso, Moreira et al. (2014) complementam que a divulgação de informações socioambientais pelas empresas tem se tornado cada vez mais recorrente, nas últimas décadas, pois, apesar da não obrigatoriedade da evidenciação de tais informações, não evidenciá-las tornou-se uma desvantagem competitiva, visto que trata-se de mecanismos necessários para reduzir a assimetria informacional entre os agentes, sendo adotada pelas organizações com o intuito de alavancar o seu valor de mercado e aumentar a credibilidade frente aos 
stakeholders, fator que favorece a obtenção de financiamentos, novos mercados e retornos financeiros (Clarkson, Fang, Li \& Richardson, 2013, Fernandes, 2013, Santos, 2016).

Vaz, Gonçalves, Niyama\& Gonçalves (2010) apontam que, com a intenção de atrair novos investidores e aumentar o nível de confiança junto ao mercado, as empresas passaram a divulgar informações adicionais sobre a gestão empresarial e ações de responsabilidade social e ambiental, ao ir além de informações obrigatórias. A partir da divulgação de informações de natureza socioambiental, a sociedade passa a ter, à sua disposição, um maior nível de disclosure, o qual permite uma visão mais ampla dos impactos e benefícios provocados pela organização em seu ambiente externo (Morais, Aquino, Ferrarezi, Gehlen \& Reis, 2015).

Com base no exposto, foi formulada uma hipótese na tentativa de responder ao problema de pesquisa.

\section{H1: A divulgação voluntária do relatório de sustentabilidade das empresas de} alto potencial poluidor, listadas na $\mathrm{B3}$, está positivamente relacionada como seu valor de mercado.

Corroborando, Uyar e Kiliç (2012) afirmam que nos mercados de capitais emergentes essa relação é pouco explorada, e as evidências são controversas, porém, a maior parte dos estudos argumenta que empresas com maiores práticas de divulgação voluntária possuem um maior valor de mercado. Ademais, Braga, Oliveira e Salotti (2009) reforçam a hipótese da relevância da informação contábil de natureza ambiental pelo fato de um bom ou mau desempenho ambiental poder resultar em complicações no desempenho econômico-financeiro ou no valor da empresa.

\section{Metodologia}

Considerando que o objetivo do presente estudo é analisar a relação do valor de mercado das empresas de alto potencial poluidor, listadas na B3, e a divulgação voluntária do relatório de sustentabilidade, no período de 2012 a 2016, o mesmo é classificado como descritivo. Na visão de Raupp e Beuren (2006), a pesquisa descritiva caracteriza-se como um estudo intermediário entre a pesquisa exploratória e a explicativa. 
Quanto à abordagem do problema, a pesquisa classifica-se como quantitativa, haja vista o emprego de métodos estatísticos para alcançar o objetivo. De acordo com Raupp e Beuren (2006), a abordagem quantitativa caracteriza-se pelo emprego de instrumentos estatísticos, tanto na coleta quanto no tratamento de dados. Quanto aos procedimentos, caracteriza-se como pesquisa documental e bibliográfica.

O universo da pesquisa corresponde a 39 empresas de alto potencial poluidor listadas na B3. A classificação, quanto ao impacto ambiental, foi estabelecida em acordo com o Anexo VIII da Lei $n^{\circ}$ 10.165/2000, que dispõe sobre a Política Nacional do Meio Ambiente. $\mathrm{O}$ anexo classifica as atividades econômicas em pequeno, médio e alto impacto ambiental, e representa o Potencial de Poluição (PP), que retrata o risco que a atividade econômica oferece, e o Grau de Utilização (GU) dos recursos naturais, relacionado ao nível de exploração do recurso.

Conforme apresentado no Quadro 1, a amostra compreendeu um total de37 empresas pertencentes ao grupo de alto potencial poluidor, visto que duas empresas (MLOG S/A e Santher) da população não dispunha dos dados necessários para análise.

Quadro 1

Empresas que compuseram a amostra da pesquisa

\begin{tabular}{|c|c|c|c|}
\hline $\begin{array}{l}\text { Potencial } \\
\text { Poluidor }\end{array}$ & $\begin{array}{c}\text { Setores da Lei } \mathrm{n}^{0} \\
10.165 / 2000\end{array}$ & Setores da B3 & Empresas \\
\hline \multirow{17}{*}{ Alto } & \multirow{4}{*}{$\begin{array}{l}\text { Extração e tratamento } \\
\text { de minerais }\end{array}$} & \multirow{4}{*}{ Minerais Metálicos } & Bradespar \\
\hline & & & Litel \\
\hline & & & MMX Mineração e MetalicosS.A \\
\hline & & & Vale S.A \\
\hline & \multirow{10}{*}{ Indústria Metalúrgica } & \multirow{4}{*}{ Artefato de Ferro e Aço } & Fibam \\
\hline & & & Mangels Indl \\
\hline & & & Panatlantica \\
\hline & & & Tekno \\
\hline & & Artefato de Cobre & Paranapanema \\
\hline & & \multirow{5}{*}{ Siderúrgica } & Ferbasa \\
\hline & & & Gerdau \\
\hline & & & Gerdau Met \\
\hline & & & Sid Nacional \\
\hline & & & Usiminas \\
\hline & \multirow{3}{*}{ Papel e Celulose } & \multirow{3}{*}{ Papel e Celulose } & Celul Irani \\
\hline & & & Fibria \\
\hline & & & Klabin S/A \\
\hline
\end{tabular}

Revista Gestão e Secretariado (GeSec), São Paulo, SP, v. 10, n. 2, mai/ago, 2019, p. 59-86. 


\begin{tabular}{|c|c|c|}
\hline & & Suzano Hold \\
\hline & & Suzano Papel \\
\hline \multirow{7}{*}{ Industria Química } & \multirow{3}{*}{ Petroquímico } & Braskem \\
\hline & & \begin{tabular}{|l|} 
Elekeiroz \\
\end{tabular} \\
\hline & & GPC Part \\
\hline & \multirow{2}{*}{ Fertilizantes e Defensivos } & Fer Heringer \\
\hline & & Nutriplant \\
\hline & \multirow[t]{2}{*}{ Químico Diversos } & Cristal \\
\hline & & Unipar \\
\hline \multirow{11}{*}{$\begin{array}{l}\text { Transporte, terminais, } \\
\text { depósitos e comércio }\end{array}$} & \multirow{9}{*}{$\begin{array}{l}\text { Exploração, Refinação e } \\
\text { Distribuição }\end{array}$} & CosanLtd \\
\hline & & Cosan \\
\hline & & Nova Oleo \\
\hline & & OGX Petroleo \\
\hline & & Pet Manguinh \\
\hline & & Petrobras \\
\hline & & Petrorio \\
\hline & & QGEP Part \\
\hline & & Ultrapar \\
\hline & \multirow[t]{2}{*}{ Equipamentos e Serviços } & LupatechS.A \\
\hline & & OSX Bra \\
\hline
\end{tabular}

Nota. Fonte: adaptado de Santos (2016).

Para a determinação das variáveis Valor de Mercado (VM), Tamanho (TAM), Endividamento (END), Rentabilidade (RENT) e Crescimento (CRESC), as informações foram coletadas na base de dados Economatica ${ }^{\circledR ; j a ́ ~ o s ~ d a d o s ~ r e l a c i o n a d o s ~ a ̀ ~ D i v u l g a c ̧ a ̃ o ~ d o ~}$ Relatório de Sustentabilidade (DIVRS)foram verificados a partir do Relatório "Relate ou Explique", que evidencia as empresas que divulgaram, ou não, os Relatórios de Sustentabilidade; estes, por sua vez, foram obtidos no site da B3, assim como a informação sobre o Índice de Sustentabilidade Empresarial (ISE).

A tabela 1 apresenta as variáveis que foram utilizadas na pesquisa, como foram calculadas e os trabalhos utilizados como base.

Tabela 1

Variáveis da pesquisa

\begin{tabular}{cccccc}
\hline VARIÁVEIS & TIPO & DESCRIÇÃo & SINAL & CÁlCULO & AUTOR \\
& & & ESPERADO & \\
\hline VM & D & Valor de Mercado & & $\begin{array}{l}\text { Logaritmo natural do } \\
\text { Valor de Mercado }\end{array}$ \\
\hline
\end{tabular}




\begin{tabular}{|c|c|c|c|c|c|}
\hline DIVRS & I & $\begin{array}{l}\text { Divulgação Voluntaria } \\
\text { Relatório de } \\
\text { Sustentabilidade } \\
\text { (dummy) }\end{array}$ & + & $\begin{array}{l}\text { (0) para aos itens que não } \\
\text { foram divulgados, (1) } \\
\text { para os } \\
\text { que foram divulgados. }\end{array}$ & $\begin{array}{l}\text { Uyar e Kiliç } \\
\text { (2012); Gordon et } \\
\text { al.(2010) }\end{array}$ \\
\hline ENDIV & I & Endividamento & + & $\begin{array}{l}\text { Exigível Total/ } \\
\text { PatrimônioLíquido }\end{array}$ & Sousa et al. (2014) \\
\hline RENT & I & Rentabilidade & + & $\begin{array}{l}\text { Lucro Líquido/ } \\
\text { PatrimônioLíquido }\end{array}$ & $\begin{array}{l}\text { Uyar e Kiliç } \\
\text { (2012); Sousa et } \\
\text { al.(2014) }\end{array}$ \\
\hline CRESC & $\mathrm{I}$ & Crescimento & + & $\begin{array}{l}\text { Variação da Receita } \\
\text { Líquidaapurada em } \\
\text { percentual pela } \\
\text { diferença entre o ano } \\
\text { posteriore o anterior }\end{array}$ & Sousa et al. (2014) \\
\hline TAM & $\mathrm{C}$ & Tamanho da Empresa & + & $\begin{array}{l}\text { Logaritmo natural do } \\
\text { ativo total }\end{array}$ & $\begin{array}{l}\text { Braga, Oliveira e } \\
\text { Salotti (2009); } \\
\text { Uyar e Kiliç } \\
(2012)\end{array}$ \\
\hline ISE & $\mathrm{C}$ & $\begin{array}{l}\text { Participação no ISE } \\
\text { (dummy) }\end{array}$ & + & $\begin{array}{l}\text { (0) para as empresas que } \\
\text { não pertencem ao ISE, (1) } \\
\text { para as que pertencem. }\end{array}$ & $\begin{array}{l}\text { Andrade et al. } \\
\text { (2013); Sousaet al. } \\
\text { (2014) }\end{array}$ \\
\hline
\end{tabular}

Legenda: D- Dependente; I - Independente; C- Controle; ISE- Índice de Sustentabilidade Empresarial

Nota. Fonte: Elaboração própria, 2017.

Para o teste da hipótese da pesquisa, foi utilizado o modelo de regressão linear múltipla com dados em painel desbalanceado, no período de 2012 a 2016.Dessa forma, apresenta-se, na expressão 1, o modelo utilizado na estimação:

VM $_{i t}=\beta 0_{i t}+\beta_{1} D_{I V R S}+\beta_{2} E_{N D I V}+\beta_{3}$ RENT $_{i t}+\beta_{4}$ CRESC $_{i t}+$ B $_{5}$ TAM $_{i t}+\beta_{6}$ ISE + $\varepsilon_{\text {it }}(1)$

O período analisado, no presente estudo, foi de 2012 a 2016, uma vez que 2012 foi o ano que a B3 passou a recomendar, às empresas listadas, que elas incluíssem, em seus relatórios anuais, o "Relate ou Explique para Relatório de Sustentabilidade ou Integrado". Essa iniciativa teve a parceria da GRI em apoio da IIRC - International Integrated Reporting Council, cujo benefício era facilitar a evidenciação de informações socioambientais para os usuários das informações. 


\section{Apresentação e Análise dos Resultados}

Nesta seção, serão abordados e discutidos os resultados da pesquisa. Inicialmente, realizou uma análise descritiva dos dados, e, posteriormente, foi realizada uma análise econométrica, a fim de definir o modelo de regressão em painel, com objetivo de testar a hipótese e, assim analisar se existe relação entre valor de mercado das empresas de alto potencial poluidor, listadas na B3, e a divulgação voluntária do relatório de sustentabilidade.

\subsection{Análise Descritiva dos Dados}

Com base nos dados apresentados na Tabela 2, observa-se que algumas variáveis, tais como ENDIV (10,1839), RENT (39.2790) e CRESC (8.3713), apresentaram uma maior dispersão dos dados em torno da média, ao contrário das variáveis DIVRS (0.5013) e ISE (0.4863), que apresentaram menor dispersão dos dados, indicando, assim, que a distribuição dos dados é assimétrica. Observa-se, ainda, que VM (13.7628) e TAM (20.8895) são as variáveis com maiores médias, e DIVRS (0.4890), CRESC (0.6884) e ISE (0.6216), com menores médias.

Tabela 2

\section{Estatística Descritiva das variáveis}

\begin{tabular}{ccccccc}
\hline Variável & Observações & Média & Desvio Padrão & Mediana & Mínimo & Máximo \\
\hline VM & 182 & 13.7628 & 2.7307 & 13.3728 & 7.4204 & 19.3561 \\
\hline DIVRS & 182 & 0.4890 & 0.5012 & 0 & 0 & 1 \\
\hline ENDIV & 184 & 3.1232 & 10.1838 & 1.8435 & -32.6294 & 54.1192 \\
\hline RENT & 184 & 2.9601 & 39.2789 & 0.0472 & -6.6172 & 532.4280 \\
\hline CRESC & 173 & 0.6884 & 8.3713 & 0.0248 & -7.0930 & 109.7711 \\
\hline TAM & 182 & 20.8895 & 2.6856 & 21.2292 & 9.3330 & 27.5258 \\
\hline ISE & 185 & 0.6216 & 0.48629 & 1 & 0 & 1 \\
\hline
\end{tabular}

Nota: VM: Valor de Mercado; DIVRS: Divulgação do Relatório de Sustentabilidade; ENDIV: Endividamento; RENT: Rentabilidade sobre o Investimento; CRESC: Crescimento da empresa;TAM: Tamanho da Empresa; ISE: Participação no ISE.

Nota. Fonte: Dados da Pesquisa, 2017.

Na Tabela 3, apresenta-se a correlação entre as variáveis, calculada a partir do modelo paramétrico de Correlação de Pearson. O coeficiente de correlação de Pearson é uma medida de associação linear entre variáveis. De acordo com Figueiredo Filho e Silva Junior (2009), o 
coeficiente de correlação de Pearson varia de -1 a 1 . O sinal indica direção positiva ou negativa do relacionamento, e o valor sugere a força da relação entre as variáveis.

Tabela 3

Correlação entre as variáveis

\begin{tabular}{cccccccc}
\hline & VM & DIVRS & ENDIV & RENT & CRESC & TAM & ISE \\
VIVRS & 1.0000 & & & & & \\
ENDIV & 0.5727 & 1.0000 & & & & & \\
RENT & 0.1978 & 0.1400 & 1.0000 & & & & \\
CRESC & -0.0318 & -0.0695 & 0.0040 & 1.0000 & & \\
TAM & -0.0671 & -0.0670 & -0.2553 & -0.0184 & 1.0000 & & \\
ISE & 0.5760 & 0.3404 & 0.1022 & -0.0530 & -0.0056 & 1.0000 & \\
\hline Nota. Fonte: Dados da Pesquisa, 2017. & 0.5809 & & & & & & \\
\end{tabular}

A partir do modelo utilizado, observou-se que as maiores relações positivas ocorreram entre VM e DIVRS (0.5727),VM e TAM (0.5760),VM e ISE (0.5809) e DIVRS e TAM (0.3404);sendo assim, à medida que uma variável obtém crescimento, a outra também obtém, ocorrendo o mesmo quando uma decresce, decrescendo, também, a outra, pois o comportamento das variáveis é sempre na mesma direção. Já RENT e DIVRS (0.0695),CRESC e ENDIV (-0.2553), e ISE e CRESC (-0.1073) obtiveram relações negativas, indicando que há relação inversa entre as variáveis, pois, à medida que uma aumenta, a outra diminui, e vice e versa.

\subsection{Análise dos Resultados Econométricos}

Após uma breve análise descritiva, a próxima etapa foi a estimação do modelo econométrico. Para tanto, com a intenção de estabelecer o painel mais indicado para a análise dos dados da pesquisa, foram realizados os testes de Chow e Hausman. 
De acordo com Magalhães e Andrade (2009), a aplicação do teste de Chow permite testar se parte ou a totalidade dos parâmetros do modelo de regressão difere, ou não, entre dois conjuntos de observações, mediante a não rejeição ou a rejeição da hipótese nula. O teste apresentou Prob $>\mathrm{F}=0,0000$, evidenciando que o modelo de efeitos fixos é mais adequado. $\mathrm{O}$ mesmo resultado se obteve com o teste de Hausman, com resultado Prob $>F=0,0000$, sendo assim, conclui-se que o melhor modelo também é o de efeito fixo.

Além disso, verificou-se, por meio dos testes de Wooldridge e Wald, que existiam problemas de autocorrelação e heteroscedasticidade, respectivamente. Para corrigir esses dois problemas, realizou-se o teste de Driscolle Kraay(1998), para os erros padrões dos coeficientes estimados por efeitos fixos, sendo esses erros robustos à heterocedasticidade, correlação temporal e espacial (Missio, 2012).

$\mathrm{Na}$ Tabela 4, apresenta-se o modelo de regressão com dados em painel, de efeitos fixos com robustez.

Tabela 4

Resultados da Regressão com Dados em Painel de Efeitos Fixos Robusta

\begin{tabular}{|c|c|c|c|c|}
\hline Var. Explicativas & Coeficiente & Erro & $t$ & p-valor \\
\hline DIVRS & -0.3576 & 0.3454 & -0.10 & 0.918 \\
\hline ENDIV & $0.0130 * *$ & 0.0050 & 2.57 & 0.015 \\
\hline RENT & $-0.0021 * * *$ & 0.0000 & -31.09 & 0.000 \\
\hline CRESC & $-0.0081 * *$ & 0.0031 & -2.60 & 0.013 \\
\hline TAM & 0.4716 & 0.0317 & 1.49 & 0.146 \\
\hline ISE & & 0 (om & & \\
\hline Constante & 12928 & 0.4017 & 32.18 & 0.000 \\
\hline Observações: & 169 & & & \\
\hline Within R-squared & 0.0579 & & & \\
\hline Teste F: & 0.0000 & & & \\
\hline \multicolumn{5}{|c|}{$\begin{array}{l}\text { Equação: VMit }=\beta 0 \text { it }+\beta 1 \text { DIVRS }+\beta 2 \text { ENDIVit }+\beta 3 \text { RENTit }+\beta 4 \text { CRESCit }+ \text { B5TAMit }+\beta 6 \text { ISE }+ \text { cit } \\
\text { Nota: } * \mathrm{p}<0,10 ; * * \mathrm{p}<0,05 ; * * * \mathrm{p}<0,01 ; \text { VM: Valor de Mercado; DIVRS: Divulgação do Relatório de } \\
\text { Sustentabilidade; CRESC: Crescimento da empresa; RENT: Rentabilidade sobre o Investimento; ENDIV: } \\
\text { Endividamento; ISE: Participação no ISE; TAM: Tamanho da Empresa. }\end{array}$} \\
\hline
\end{tabular}

Nota. Fonte: Dados da Pesquisa, 2017.

Analisando o resultado da regressão de efeitos fixos, ora destacado na Tabela 4, é possível afirmar que todos os coeficientes do modelo são diferentes de zero (Prob $>=0,0000$ ). Nota-se, ainda, que a variável ISE foi omitida do modelo por se tratar de uma variável dummy 
fixa ao longo do painel, e, como consequência, não se podem estimar seus coeficientes na regressão com dados em painel (Santoset al., 2016).

Os resultados do modelo mostram significância estatística para as variáveis ENDIV, RENT e CRESC, ao nível de 5\%, 1\% e 5\%, respectivamente. Por outro lado, as variáveis independentes, TAM e DIVRS, não apresentaram significância estatística, ao nível de 1\%, 5\% e $10 \%$.

Considerando que a variável ENDIV apresentou significância estatística (p-valor = 0,015), ao nível de 5\%, e coeficiente positivo (0.0130), pode-se afirmar que há uma relação direta com o VM, ou seja, quanto maior o endividamento da entidade, maior o seu valor de mercado. Esses resultados corroboram as pesquisas de Sousa et al. (2014) e Santos et al. (2016).

A rentabilidade (RENT) foi uma variável estatisticamente significante ( $\mathrm{p}$-valor $=$ 0,0000), e com coeficiente negativo (-0.0021), concluindo-se, assim, que a rentabilidade possui uma relação indireta com a variável dependente (VM).Nesse sentido, nota-se que quanto maior a rentabilidade das empresas, menor será seu valor de mercado. O resultado obtido é consistente com o estudo de Neves Junior, Lima e Lima (2011), e contrário às pesquisas de Nogueira, Curi e Nuintin (2012) e Santos et al. (2016), no qual observa-se que a rentabilidade tem um razoável poder de influência sobre o valor de mercado das empresas.

No tocante à variável CRESC, também, verificou-se uma relação significante(p-valor $=0,013)$ e indireta(coeficiente $=-0.0081$ )em relação VM. Sendo assim, é possível inferir que, quanto maior for o crescimento da companhia, menor será seu valor de mercado. Não foram encontrados estudos anteriores que corroborassem este resultado, visto que esperava-se que, quanto maior o crescimento da empresa, maior seria o valor de mercado, e, por consequência, geraria maior segurança para os investidores, o que implicaria numa margem de influência para atraí-los.

Dentre os resultados contrários verificados na literatura, destacam-se os estudos de Sousa et al., (2014) e Silva e Silva (2017), que, embora possuam uma relação significante entre crescimento (CRESC) e valor de mercado (VM), têm uma relação direta, pois, de acordo 
com Sousa et al., 2014, pressupõe-se que as expectativas de crescimento provoquem efeitos positivos no valor de mercado das companhias, quando houvesse crescimento da empresa.

Tratando da variável TAM, ela não mostrou significância estatística(p-valor = 0,146)em relação à variável dependente (VM).Com isso, sugere-se que não há relação explicativa da variável TAM sobre o valor de mercado. O coeficiente obtido desta variável foi (0.4716), e, mesmo sem significância, houve relação direta, remetendo àideia de que, quanto maior a empresa, maior o seu valor de mercado. O resultado corroborou o estudo de Cunha e Ribeiro (2008) e Braga, Oliveira e Salotti (2009), que também não demonstraram significância em seus resultados, e apresentaram uma relação direta. Por outro lado, estudos como o de Santos, Araújo e Leite Filho (2016) obtiveram o resultado de coeficiente negativo, sugerindo uma relação inversa do tamanho com o valor de mercado.

Por fim, a variável independente DIVRS também não retratou significância estatística ( $\mathrm{p}$-valor $=0,918)$,e apresentou coeficiente indireto(-0.3576),em relação à variável dependente (VM).Dessa maneira, pode-se inferir que ela não possui valor preditivo sobre o valor de mercado das empresas. Logo, com base na análise dos resultados apresentados, pode-se rejeitar ou não rejeitar a hipótese de pesquisa.

H1: O valor de mercado das empresas de alto potencial poluidor listadas na B3 esta positivamente relacionada com a divulgação voluntária do relatório de sustentabilidade.

De acordo com os resultados estatísticos, a variável divulgação voluntária de relatório de sustentabilidade (DIVRS) não possui poder explicativo da alteração (aumento ou redução) do valor de mercado das empresas. Sendo assim, rejeita-se a hipótese de que existe relação significante entre o valor de mercado das empresas de alto potencial poluidor, listadas na B3, e a divulgação voluntária do relatório de sustentabilidade.

Resultado semelhante encontrou-se no estudo de Sousa et al.(2014),os quais observaram que a relação da divulgação voluntária de informações sociais e o valor de mercado não apontaram significativa estatística; e contrário, no estudo de Gordon et al. (2010), que constataram que as divulgações voluntárias têm um efeito positivo no valor de mercado de uma empresa. Todavia, Sousa et al. (2014) identificaram que a divulgação 
voluntária de informações sociais ainda é muito pequena, entre as companhias de seu estudo, e que, apenas, dois setores (elétrico e petróleo, gás e bicombustíveis) possuem índice de divulgação social voluntária acima de $50 \%$.

As evidencias desta pesquisa contraria a premissa de que a divulgação do relatório de sustentabilidade exerce influência positiva no valor de mercado das empresas. De acordo com Morais et al. (2015), existe um poder implícito nos relatórios de sustentabilidade divulgados pelas empresas, sendo uma das formas mais utilizadas para a evidenciação das ações sustentáveis e sociais. Nesse mesmo sentido, Santos et al. (2016) apontam, em seus resultados, que as práticas de divulgação de informações sociais, têm efeito positivo na criação de valor para os acionistas, uma vez que os investidores são capazes de detectar o nível de compromisso corporativo com o desenvolvimento sustentável.

Nossa (2002) enfatiza que as organizações têm observado que para conseguirem, principalmente, desempenho e lucratividade, é necessário que elas expandam o atendimento à demanda de informações ambientais, e, aos poucos, vão reagindo a essas pressões, incluindo, em suas estratégias, práticas gerenciais em relação às questões ambientais.

\section{Considerações Finais}

O objetivo geral desta pesquisa foi analisar a relação do valor de mercado das empresas de alto potencial poluidor, listadas na B3, e a divulgação voluntária do relatório de sustentabilidade, no período de 2012 a 2016. A amostra do estudo corresponde às empresas que apresentaram dados suficientes para a construção das variáveis necessárias na pesquisa, classificadas com alto grau de potencial poluidor, listadas na B3, de acordo com o Anexo VIII da Lei ${ }^{\circ}$ 10.165/2000, que dispõe sobre a Política Nacional do Meio Ambiente.

Os dados analisados foram coletados na base de dados Economática ${ }^{\circledR}$, organizadas em um painel desbalanceado, de efeito fixos com robustez, uma vez que não foi possível verificar todos os dados, para todas as empresas classificadas como de alto potencial.

Para alcançar o objetivo da pesquisa, utilizou-se as premissas da Teoria da Divulgação Voluntária, a qual defende que a divulgação dos relatórios de sustentabilidade traz benefícios 
diretos e indiretos para a empresa, principalmente auxiliando os stakeholders na tomada de decisões.

No tocante à análise da hipótese $($ H1: $\mathrm{O}$ valor de mercado das empresas de alto potencial poluidor listadas na B3 esta positivamente relacionada com a divulgação voluntária do relatório de sustentabilidade.), não houve significância estatística, levando a rejeição da hipótese testada; além disso, a variável explicativa VM apresentou um sinal de coeficiente negativo, o que remete à relação inversa entre o valor de mercado e a divulgação do relatório de sustentabilidade.Com isso, a variável DIVRS, neste estudo, não apresentou poder para predizer as alterações (positivas ou negativas) no valor de mercado (VM) das empresas da amostra.

As demais variáveis, ENDIV,RENT e CRESC, obtiveram relação significante, sendo o endividamento (ENDIV) refletido de forma positiva, enquanto que a rentabilidade (RENT) e crescimento da empresa (CRESC), refletidas de forma negativa sobre o valor de mercado.

Vale destacar que os resultados mensurados, no presente estudo, podem ter sofrido influências de algumas limitações ocorridas no decorrer de seu desenvolvimento, tais como:

(i) o fato das empresas não disponibilizarem algumas informações financeiras, mesmo havendo a obrigatoriedade, já que são empresas de capital aberto, acarretando exclusão das mesmas do estudo;

(ii) fragilidade da métrica utilizada para determinação da variável explicativa (DIVRS), visto que só se verificou se a empresa divulga ou não divulga o relatório de sustentabilidade;

(iii) poucos estudos que remetem a relação do valor de mercado com a divulgação voluntária do relatório de sustentabilidade, impossibilitando, assim, uma confrontação dos resultados, desta pesquisa, com a de outros estudos sobre a temática.

Como sugestão para pesquisas futuras, recomenda-se: (i) a observação das limitações acima elencadas; (ii) a utilização de outras variáveis e métricas; (iii) utilização dos outros 
níveis de classificação (pequeno e médio) de impacto ambiental, disposto no Anexo VIII da Lei $n^{\circ} 10.165 / 2000$.

A contribuição desta pesquisa para a literatura consiste em demonstrar se existe relação entre o valor de mercado e o relatório de sustentabilidade, no mercado de capitais, das empresas classificadas no alto nível de potencial poluidor, após apresentação do Projeto de Lei do Senado, o qual obrigou, às empresas, a divulgação do relatório de sustentabilidade.

Embora a literatura considere a necessidade de tal informação, tornando-se a divulgação do relatório de sustentabilidade um diferencial, principalmente quando ocorre o crescimento da competitividade entre as empresas, e no auxílio aos stakeholders na tomada de decisões, o resultado do presente estudo mostrou que o fato das empresas publicarem relatórios de sustentabilidade não implica, necessariamente, em vantagem em relação às outras empresas, no que se refere ao valor de mercado.

Uma possível explicação, para o resultado encontrado, refere-se à não influência e/ou utilização das informações apresentadas nesses relatórios na tomada de decisão dos stakeholders. $\mathrm{Ou}$, ainda, pelo fato das empresas de alto impacto poluidor serem fiscalizadas mais rigorosamente por órgãos reguladores, e, consequentemente, já atenderem requisitos exigidos por leis ambientais.

Todavia, cabe investigações em futuros estudos para saber se o resultado obtido não foi em virtude das limitações que ocorreram no desenvolvimento da pesquisa; ou o fato da amostra ser de um segmento muito regulamentado, e, com isso, os stakeholders acabam não exigindo tanto a evidenciação do relatório de sustentabilidade, por considerarem estas empresas interessantes para investirem, tendo em vista que elas já sofrem uma grande fiscalização.

\section{Referências}

Andrade, L. P.; Bressan, A. A.; Iquiapaza, R. A.; \& Moreira, B. C. M. (2013). Determinantes de Adesão ao Índice de Sustentabilidade Empresarial da BM\&FBOVESPA e sua Relação com o Valor da Empresa. Revista Brasileira de Finanças, 11(2), pp. 181-213. 
Antunes, M. T. P. (2000). Capital intelectual. São Paulo: Atlas.

Bertoncello, S. L. T., \& Júnior, J. C. (2007). A importância da Responsabilidade Social Corporativa como fator de diferenciação. FACOM-Revista da Faculdade de comunicação da FAAP, (17), pp. 70-76.

Raupp, F. M., \&Beuren, I. M. (2006). Metodologia da Pesquisa Aplicável às Ciências. Como elaborar trabalhos monográficos em contabilidade: teoria e prática. São Paulo: Atlas.

Bm\&Fbovespa. (2018). Empresas Listadas: Relatório de Sustentabilidade ou Similar. Recuperado de: $<$ http://www.bmfbovespa.com.br/pt br/institucional/sustentabilidade/nasempresas/relate-ou-explique/>.

Botelho, T. (2006). Responsabilidade social e ambiental: reação do mercado de açõesbrasileiras. 2006. Dissertação de MestradoemAdministração, PontifíciaUniversidadeCatólica do Rio de Janeiro - PUC, Rio de Janeiro, Brasil.

Braga, J. P., Oliveira, J. R. S., \&Salotti, B. M. (2009). Determinantes do Nível de Divulgação Ambiental nas Demonstrações Contábeis de Empresas Brasileiras. Revista de Contabilidade da UFBA, 3(3), pp. 81-95.

Cavalcante, L. R. M. T., Bruni, A. L., \& Costa, F. J. M. (2007). Sustentabilidade Empresarial e Desempenho Corporativo: Uma Análise do Mercado Brasileiro de Ações. Anais do Encontro da ANPAD, RJ, Brasil, 31.

Cintra, Y. C. (2011).A integração da sustentabilidade às praticas de controlegerencial das empresas no Brasil. 2011. Tese de DoutoradoemCiências Contábeis, Universidade de São Paulo, São Paulo, Brasil.

Clarkson, P. M., Fang, X., Li, Y., \& Richardson, G.(2013).The relevance of environmental disclosures: Are such disclosures incrementally informative? Journal of Accounting and Public Policy, 32(5), pp. 410-431.

Corrêa, M. D. (2009). Relação entre o nível de divulgaçãoambiental $e \quad o$ desempenhoambiental das empresascomponentes do índiceBovespa. Dissertação de MestradoemContabilidade, Universidade Federal do Paraná, Curitiba, Brasil.

Cruz, P. R. (2005).Responsabilidade social e imagemempresarial: o discurso da U\&M Mineração e Construção S/A. Juiz de Fora: UFJF; Facom; 2005, f. 114. Projeto Experimental do Curso de Comunicação Social / Jornalismo (Bacharelado).

Cunha, J. V. A.,\& Ribeiro, M. S. (2008). Divulgação voluntária de informações de natureza social: um estudo nas empresas brasileiras. Revista de Administração - Eletrônica, 1(6), pp. $1-23$.

Dahlsrud, A. (2008). How corporate social responsibility is defined: an analysis of 37 definitions. Corporate social responsibility and environmental management, 15(1), pp. 113.

Deegan, C. (2002). The legitimizingeffectof social andenvironmentaldisclosures: a theoreticalfoundation. Accounting, AuditingandAccountabilityJournal, Bradford, 15(3), pp. 282-311. 
Dias Filho, J. M. (2007).Políticas de EvidenciaçãoContábil: Um EstudodoPoderPreditivo e Explicativo da Teoria da Legitimidade. Anais do Encontro Nacional dos Programas de PósGraduaçãoemAdministração - ANPAD, Rio de Janeiro, Rio de Janeiro, Brasil, 31.

Driscoll, J. C., \&KraayA. C. (1998).ConsistentCovariance Matrix EstimationwithSpatiallyDependentPanel Data.ReviewofEconomicsandStatistics, 80.

Farias, M.R.S. (2004). Divulgação do passivo: um enfoque sobre o passivo 15 contingente no setor químico e petroquímico brasileiro. Dissertação Mestrado em Ciências Contábeis, Faculdade de Economia, Administração e Contabilidade da Universidade de São Paulo, São Paulo, Brasil.

Fernandes, S. M. (2013). Fatores que Influenciam o Disclosure Ambiental: Um Estudo nas Empresas Brasileiras no Período de 2006 a 2010. Revista Ambiente Contábil, Natal/RN, 5(2), pp. 250-267.

Field, A. (2009). Descobrindo a Estatística Usando o SPSS. 2 ed. Porto Alegre: Artmed.

Figueiredo Filho, D. B., \& Silva Junior, J.A. (2009). Desvendando os Mistérios do Coeficiente de Correlação de Pearson (r). Revista E-Xacta (online), 18(1).

Gil, A. C. (2008).Métodos e Técnicas de Pesquisa Social. 6. ed. São Paulo: Atlas.

Gordon, L. A., Loeb, M. P., \&Sohail, T. (2010). Market value of voluntary disclosures concerning information security.MIS Quarterly, 34(3), pp. 567-594.

GRI - Global ReportingInitiative.(2013). Diretrizes para Relatório de Sustentabilidade.Recuperado de: <https://www.globalreporting.org/resourcelibrary/GRIG3-Brazilian-Portuguese-Reporting-Guidelines.pdf $>$.

GRI - Global ReportingInitiative.(2015). Manual de Implementação.Disponívelem: $<$ https://www.globalreporting.org/resourcelibrary/Brazilian-Portuguese-G4-PartTwo.pdf $>$.

Hendriksen, E. S., \& Van Breda, M. F. (1999).Teoria da Contabilidade. $5^{\text {a }}$ ed., São Paulo: Atlas.

Huang, C. L., \& Kung, $\quad$ F. $\quad$ H. $\quad$ (2010).Drivers ofenvironmentaldisclosureandstakeholderexpectation: evidencefrom Taiwan. Journalof Business Ethics, 96(3), pp. 435-451.

Ho, C. (2005). Corporate governanceandcorporatecompetitiveness: nainternationalanalysis.Corporate Governance: AnInternationalReview, 13(2), pp. 211253.

Lima, et al. (2012).Contabilidadeambiental: um estudosobre a evidenciação das informaçõesambientaisnasdemonstraçõescontábeis das grandes empresasbrasileiras. RevistaEletrônica de Administração (Online),11(1), pp. 1-14.

Lima, G. A. S. F. (2007).Utilização da Teoria da Divulgação para avaliação da relação do nível de disclosurecom o custo da dívida das empresas brasileira. Tese de Doutorado em 
Controladoria e Contabilidade, Faculdade de Economia, Administração e Contabilidade daUniversidade de São Paulo, São Paulo/SP, Brasil.

Lucena, W. G. L., \& Pereira, M. L. (2016).Determinantes da divulgação voluntária do relatório de sustentabilidade nas empresas de energia elétrica e telecomunicações listadas na BM\&FBOVESPA. Anais do Congresso Brasileiro de Custos,Porto de Galinas, Pernambuco, Brasil, 23.

Magalhães, S. R., \&Andrade, E. A. (2009). Testes à igualdade dos parâmetros de um modelo de regressão: uma aplicação especial das variáveis binárias (dummy). Revista E-Xacta (online), 2(3).

Monteiro, P. R. A., \& Ferreira, A. C. S. (2007). A evidenciação da informação ambiental nos relatórios contábeis: um estudo comparativo com o modelo do ISAR/UNCTAD. Revista de Gestão Social e Ambiental, 1(1), pp. 82-101.

Missio, F. J. (2012). Câmbio Real e Crescimento: Novas Evidências Empíricas. Anais do Encontro Internacional da Associação Keynesiana Brasileira Keynesiana, São Paulo, SP, Brasil, 5.

Morais, C. M., De Aquino, G. A. Z., Ferrarezi, J. R. H., Gehlen, K. R. H, \&Dos Reis, L. G. (2015).Relatórios de Sustentabilidade: Uma Análise Bibliométrica da Produção Acadêmica Brasileira. Anais do Encontro Internacional Sobre Gestão empresarial e Meio Ambiente - ENGEMA,São Paulo, SP, Brasil, 17.

Moreira, N. B., Dias Filho, J. M., Gomes, S. M. S., \& Conceição, M. G. (2014). Fatores que impactam a divulgação voluntária de informações socioambientais na percepção dos gestores. Reunir: Revista de Administração, Contabilidade e Sustentabilidade, 4(1), pp. 62-82.

Murcia, F. D.,\& Santos, A. (2009). Fatores determinantes do nível de disclosure voluntário das companhias abertas no Brasil. Revista de Educação e Pesquisa em Contabilidade, 3(2), pp. 72-95.

Nagano, R. T., Kassai, J. R., Kussaba, C. T., \& Carvalho, L. N. G. (2014).A Evolução dos relatórios de sustentabilidade e a necessidade da Obrigatoriedade de sua asseguração por terceiros. Anais do II Simpósio Internacional de Gestão de Projetose I Simpósio Internacional de Inovação e Sustentabilidade, São Paulo, SP, Brasil.

Neves Junior, I. J., Lima, R. R., \& Lima, T. R. (2012).Valor da Empresa e sua Relação com a estrutura de capital, rentabilidade: um estudo empírico das 1000 empresas melhores listadas na Revista Exame. Anais do Simpósio de Gestão da Inovação Tecnológica SEGeT, Resende, RJ, Brasil, 8.

Nogueira, L. R.T., Curi, M. A., \&Nuintin, A. A. (2012). Relação da rentabilidade e da liquidez com o valor de mercado das empresas brasileiras de capital aberto: estudo do setor de energia elétrica. Revista de Administração da UEG,3(1), pp. 75-97.

Nossa, V. (2002). Disclosure ambiental: uma análise do conteúdo dos relatórios ambientais de empresas do setor de papel e celulose em nivel internacional. Tese de Doutorado em Ciências Contábeis, Universidade de São Paulo, SP, Brasil. 
Rover, S., Borba, J. A.,\& Murcia, F. D. (2009).Características do disclosureambiental de empresas brasileiras potencialmente poluidoras: análise das demonstrações financeiras e dos relatórios de sustentabilidade do período de 2005 a 2007. Revista Contemporânea de Economia e Gestão, 7(1), pp.23-36.

Rufino, M. A., \& Monte, P. A. (2014). Fatores que explicam a divulgação de informações voluntárias das 100 empresas com ações mais negociadas na BM\&FBOVESPA. Anais do Congresso Anpcont, Rio de Janeiro, RJ, Brasil, 8.

Santos, L. M. S. (2016). Fatores explicativos da evidenciação de informações ambientais das empresas potencialmente poluidoras listadas na BM\&FBovespa. Dissertação de Mestrado em Ciências Contábeis, Universidade Federal da Paraiba, João Pessoa, PB, Brasil.

Santos, L. M. S., Araújo, R. A. M., \& Leite Filho, P. A. M. (2016). Divulgação voluntária e o valor de mercado: um estudo nas empresas brasileiras de construção civil listadas na BM\&FBovespa. Anais do Congresso Anpcont, Ribeirão Preto, SP, Brasil, 10.

Silva, J. P., \& Silva, D. C. (2017). Análise da relação entre estrutura de capital, crescimento, lucratividade e valor de mercado das companhias brasileiras de capital aberto. $R M C$ Revista Mineira de Contabilidade, Belo Horizonte, 18(1), pp. 15-25.

Slewinski, E., Gonçalves, M. N., \&Sanches, S. L. R. (2015).Determinantes da divulgação do relatório de sustentabilidade ou do relato integrado das empresas listadas na BM\&FBovespa. Anais do Congresso Anpcont, Curitiba, PR, Brasil, 9.

Sousa, C. B. (2013).Valor de Mercado e disclosurevoluntário: estudo empirico em companhias listadas na B3. Dissertação de Mestrado em Ciências Contábeis, Fundação Escola de Comercio Armando Álvares Penteado - FECAP, São Paulo/SP, Brasil.

Sousa, C. B., Silva, A. F., Ribeiro, M. S.,\&Weffort, E. F. J. (2014). Valor de mercado e disclosure voluntário: estudo empírico em companhias listadas na BM\&FBOVESPA. Revista Ambiente Contábil, 6(2), pp. 94-115.

Souza, M. A., Rásia, K. A.,\& Jacques, F. V. (2010). Evidenciação de informações ambientais pelas empresas integrantes do índice de sustentabilidade empresarial - ISE. Revista de Contabilidade e Controladoria, 2(1), pp. 75-139.

Tinoco, J. E. P. (2010). Balanço social e o relatório de sustentabilidade. São Paulo: Atlas.

Uyar, A., \&Kiliç, M. (2012). Value relevance of voluntary disclosure: evidence from Turkish firms. Journal of Intellectual Capital, 13(3), pp. 363-376.

Vaz, A. C., Gonçalves, R. S., Niyama, J. K., \&Gonçalves, A. O. (2010). Análise Comparativa Sobre Informações Voluntárias Divulgadas: O Social Disclosuredas Empresas LatinoAmericanas Listadas na Nyse. Revista de Educação e Pesquisa em Contabilidade REPEC, 4(1), pp. 38-59.

Verrecchia, R. (2001). Essays on disclosure.Journal of Accounting and Economics, 32, pp. 97-180. 
Salotti, B. M., \& Yamamoto, M. M. (2008). Divulgação voluntária da demonstração dos fluxos de caixa no mercado de capitais brasileiro. Revista Contabilidade \& Finanças, 19 (48), pp. 37-49.

Zaro, E. S., Pastre, F., \&Albeton, L. (2015).Asseguração dos relatórios de sustentabilidade das empresas que compõem a carteira do índice de sustentabilidade empresarial 2013. Revista de Contabilidade do Mestrado em Ciências Contábeis da UERJ (online), 20 (1), pp. 47-63.

Submetido em: 15.08 .2018

Aceito em: 17.04.2019 